\title{
O CORPO COMO CORPUS: lugares do ensino de literatura para estudantes surdos
}

\author{
Danielle Cristina Mendes Pereira Ramos ${ }^{1}$
}

\begin{abstract}
RESUMO
Este trabalho propõe-se a pensar as relações entre letramentos literários de estudantes surdos e os discursos e práticas de identidades e de poder, que tangenciam concepções sobre conhecimento, texto e literatura, presentes nos currículos universitários e nas comunidades surdas. Aponta para a reflexão sobre a literatura como um caminho de resistência, em uma sociedade excludente em relação às minorias culturais e linguísticas, diante dos discursos oficiais e contraditórios sobre inclusão, amparados pelo neoliberalismo. O trabalho tem como arcabouço teórico os estudos de Bhabha (1993) sobre o conceito de diferença cultural; os de Canclini (2006), sobre Hibridismo; e os Novos Estudos de Letramentos, sobretudo os de Street (2014), referentes às concepções plurais de letramentos e suas conexões com contextos de poder. Pretendemos demonstrar a premência de reconhecer as especificidades socioculturais dos grupos surdos nos processos de educação formal, assim como as pertinentes às manifestações literárias em Libras Língua Brasileira de Sinais - que possuem como corpus privilegiado o próprio corpo em movimento, expressas através de uma língua tridimensional, visual e espacial, em estratégias de performance.
\end{abstract}

Palavras-chave: Inclusão. Surdos. Letramentos.

\section{THE BODY AS CORPUS: the spaces of literature teaching for deaf students}

\begin{abstract}
The main aim of this work is to discuss the connections between deaf students' literary literacies and discourses and practices of identities and power, which concerned to conceptions about knowledge, text and literature, which can be found at universities curriculum and in communities. It points to the reflection on literature as a path of resistance, in an exclusionary society in relation to cultural and linguistic minorities, facing the official and contradictory discourses on inclusion, supported by neoliberalism. The work has as theoretical framework the studies of
\end{abstract}

\footnotetext{
1 Doutora em Literatura Comparada (Universidade Federal Fluminense - UFF) e pesquisadora de pós-doutorado na FFLCH/Universidade de São Paulo (USP). Professora adjunta da Faculdade de Letras da Universidade Federal do de Janeiro (UFRJ) e professora colaboradora do Mestrado Profissional em Educação Bilíngue do Instituto Nacional de Educação de Surdos (INES). Rio de Janeiro, Rio de Janeiro, Brasil. Orcid ID: https://orcid.org/0000-0001-6439-748X. E-mail: danielle@letras.ufrj.br
} 
Bhabha (1993) on the concept of cultural difference; those of Canclini (2006), on Hybridism; and the New Studies of Literacies, especially those of Street (2014), that refers to the plural conceptions of literacies and their connections with contexts of power. We intend to demonstrate the urgency of recognizing the sociocultural specificities of deaf groups in formal education processes, as well as those pertinent to the literary manifestations in Libras - Brazilian Sign Language - that have as their corpus the body itself in movement, expressed through a three-dimensional language, visual and spatial, in performance strategies.

Keywords: Inclusion. Deaf. Literacies.

\section{EL CUERPO COMO CORPUS: el espácio de la enseñanza de literatura para estudiantes sordos}

\section{RESUMEN}

Este trabajo se propone a pensar las relaciones entre la literacías literarias de estudiantes sordos y discursos y prácticas de identidades y de poder, que tangencian concepciones sobre conocimiento, texto y literatura, presentes en los currículos universitarios y en las comunidades sordas. Proponemos una reflexión acerca de la literatura como un camino de resistencia, en una sociedad excluyente en relación a las minorías culturales y lingüísticas, ante los discursos oficiales y contradictorios sobre inclusión, amparados por el neoliberalismo. El trabajo tiene como marco teórico los estudios de Bhabha (1993) sobre el concepto de diferencia cultural; los de Canclini (2006), sobre Hibridismo; y los Nuevos Estudios de Literacías, sobre todo los de Street (2014), referente a las concepciones plurales de las literacías y sus conexiones con contextos de poder. Se pretende demostrar la premura de reconocer las especificidades socioculturales de los grupos sordos en los procesos de educación formal, así como las pertinentes a las manifestaciones literarias en Libras - Lengua Brasileña de Señales - que poseen como corpus privilegiado el propio cuerpo en movimiento, expresadas a través de una lengua tridimensional, visual y espacial, en estrategias de performance.

Palabras clave: Inclusión. Sordos. Literacías.

\section{QUESTÕES SOBRE O ENSINO SUPERIOR DE SURDOS NO BRASIL}

Este trabalho tem como objetivo discutir faces dos letramentos literários de surdos e suas relações com o ensino formal de literatura. Nossa proposta é a de refletir sobre a relação entre o lugar ainda periférico ocupado pelas disciplinas de Literatura nos currículos escolares dos cursos de Letras-Libras, face a dois contextos: a produção e a circulação de modalidades poéticas surdas contemporâneas; e as concepções sobre conhecimento, texto e literatura presentes nos discursos de alunos surdos, frente à visão tradicional 
sobre a literatura, vinculada estritamente ao modo escrito, e presente no universo acadêmico, em um âmbito dominante.

Nossa hipótese é a de que na literatura em língua de sinais o corpo dáse como corpus poético tecido pela experiência linguística visuoespacial em transcendência ao texto escrito. Trata-se de uma forma artística radicalmente distinta da literatura grafocêntrica, com potencial criativo agudo e inovador, em exercícios de performance. Aponta-se, assim, a necessidade de pensar novos caminhos para o ensino de literatura para surdos, no qual caibam também as produções contemporâneas artísticas surdas em línguas de sinais, que já circulam nas comunidades surdas.

O trabalho ancora-se em parte de uma pesquisa exploratória e qualitativa (CHIZZOTTI, 2008) sobre letramentos de graduandos surdos, com esteio teórico nos Novos Estudos de Letramentos e nos Estudos Culturais. A pesquisa foi realizada a partir de investigação bibliográfica; análise documental; e estudo de caso intrínseco (STAKE, 1995), envolvendo quinze alunos surdos falantes de Libras como primeira língua, matriculados em cursos de licenciatura de Letras-Libras de uma universidade pública brasileira, com idade entre 20 e 38 anos. Para tanto, a coleta de dados, realizada entre os anos de 2017 e 2019, foi realizada por meio de observação, depoimentos e entrevistas com os referidos discentes.

Intentamos, com este artigo, lançar algumas luzes sobre as questões aqui apontadas, através do delineamento de um breve panorama sobre o ensino superior de surdos no Brasil, da discussão sobre os conceitos de texto e literatura bem e a indagação sobre a forma como estes impactam concepções acerca do ensino de literatura para surdos; e da reflexão sobre este, a partir dos discursos de graduandos surdos. Ao considerarmos ser incontornável no ensino de literatura a colocação dos alunos surdos como protagonistas criativos, exploramos três modalidades poéticas contemporâneas surdas, e, posteriormente, discutimos seus possíveis espaços nos currículos dos cursos de licenciatura em Letras-Libras.

De acordo com os dados levantados pelo censo de 2010, elaborado pelo Instituto Brasileiro de Geografia e Estatística, o IBGE, o Brasil conta com 
uma população de 9,7 milhões de surdos; dentre estes, mais de 2 milhões possuem o que o instituto qualifica como surdez severa. Quando falamos dos surdos brasileiros, portanto, nos dirigimos a uma minoria muito mais no sentido simbólico e cultural do que no qualitativo. Estamos diante de uma parcela significativa da população, dentre a qual se destacam vários sujeitos que se identificam como pertencentes a um grupo linguístico que tem como primeira língua não a portuguesa, mas a Língua de Sinais Brasileira, doravante Libras.

Diante de tal cenário, reivindicamos aqui a concepção dos surdos como uma categoria cultural, com identidades e língua próprias, rechaçando, assim, a percepção clínica da surdez, que a postula como deficiência. Ao rejeitarmos o rótulo de deficientes aos surdos, reconhecemos a sua competência cognitiva e a legitimidade das línguas de sinais, através das quais pensam e se comunicam.

Alinhamo-nos à postura defendida por pesquisadores desde a década de 60 do século XX, quando William Stokoe apresentou seus estudos sobre a língua de sinais americana e comprovou ser absurdo conceber a ASL (American Sign Language) ou quaisquer outras línguas de sinais como elementos de mímica ou de pantomima, como vigia à época. Stokoe comprovou a legitimidade da ASL como uma língua completa que "satisfazia todos os critérios linguísticos de uma língua genuína, no léxico e na sintaxe, na capacidade de gerar um número infinito de proposições" (SACKS, 1998, p. 70). Portanto, consideramos a Libras como uma língua capaz de levar o sujeito à compreensão sensível do mundo e à elaboração de pensamentos abstratos. Tal compreensão endossa a retirada dos grupos surdos usuários de Libras de um lugar construído pelo discurso clínico, uma vez que a ideia de deficiência torna-se incoerente, já que os estes são capazes da aquisição linguística e da comunicação através de uma língua cuja modalidade é visual e espacial.

Afirmamos aqui as experiências surdas pela perspectiva cultural, ao ressaltarmos a diferença linguística presente em comunidades surdas. Marcamos franca e forte oposição ao discurso clínico que concebe "o 
surdo" por um prisma estereotipado e essencialista, não considerando a pluralidade dos sujeitos surdos e evidenciando percepções incoerentes, ao entender a surdez como uma falta a ser corrigida. Tais concepções mostramse defasadas ao reconhecemos, como pontua Gesser, que os falantes de línguas de sinais podem expressar "sentimentos, emoções e quaisquer ideias ou conceitos abstratos" (2009, p. 23).

Diante do exposto, percebemos que, apesar do reconhecimento das línguas de sinais como línguas, ainda são complexas as implicações vividas pelos falantes de Libras, geradas pelo pertencimento a um grupo cultural cuja identidade é fortemente marcada por uma língua minoritária², de modalidade visual e espacial ${ }^{3}$, em uma sociedade na qual predomina uma língua oral e escrita, a saber, a língua portuguesa.

Desse contexto, deriva uma sensação de alijamento reportada com constância nos discursos de muitos surdos, conexa a discursos pejorativos quanto às suas experiências e às fragilidades que envolvem, neste contexto, o ensino de língua portuguesa como segunda língua (BOTELHO, 2005).

Essa sensação é reportada por estudantes universitários surdos mesmo após o reconhecimento oficial da Libras como língua brasileira, que abriu caminho para o delineamento de novas percepções sobre as culturas surdas bem como permitiu mudanças sensíveis na educação dos surdos, chanceladas pela legislação do país.

Resultado de anos de lutas e esforços dos movimentos surdos, a Libras passou a ser considerada como língua oficial no Brasil em 24 de abril de 2002, através da Lei 10.436. Além do reconhecimento da Libras "como meio legal de comunicação e expressão" (BRASIL, 2002), destaca-se na lei o Artigo $4^{\circ}$, que faz referência à exigência da inclusão do ensino de Libras nos cursos

\footnotetext{
2 Cabe aqui lembrar a multiplicidade linguística do Brasil; além da língua portuguesa, mais de duzentas outras línguas são faladas neste país (DAMULAKIS, 2017).

3 Além da modalidade visual e espacial, existe o registro escrito da Libras, pela chamada escrita de sinais - a sign writting - ou Escrita de Sinais. Entretanto, a Escrita de Sinais ainda não é amplamente utilizada pelos surdos usuários de Libras como primeira língua. Em seu cotidiano de comunicação escrita, eles tendem a usar com maior frequência (quando não unicamente) a segunda língua, a portuguesa. Ressaltamos que existem esforços, especialmente os advindos dos pesquisadores surdos, em divulgar e incentivar o uso da Escrita de Sinais no Brasil.
} 
de formação de Educação Especial, de Fonoaudiologia e de Magistério, nos níveis médio e superior.

Por sua vez, o Decreto n. 5.626, de 22 de dezembro de 2005, regulamentou a Lei 10.436 e traçou critérios específicos para o que categoriza como "pessoa surda", a saber, aquela que "por ter perda auditiva, compreende e interage com o mundo por meio de experiências visuais, manifestando sua cultura principalmente pelo uso da Língua Brasileira de Sinais - Libras" (BRASIL, 2015).

Além desse importante reconhecimento, o referido decreto ratificou a oferta da disciplina de Libras nos cursos já citados pela Lei de 2002 ao propor, em seu artigo $4^{\circ}$., a formação de docentes de Libras, com vista à atuação no segundo segmento do Ensino Fundamental, no Ensino Médio e no Ensino Superior, em curso de graduação em licenciatura plena em LetrasLibras - ou em Libras/Língua Portuguesa como segunda língua. A oferta de cursos de Letras-Libras também previu a modalidade de Bacharelado, voltada à formação de tradutores e intérpretes.

As diretrizes legais desenharam um cenário de inserção, ampliando o número de surdos no Ensino Superior brasileiro. O Censo da Educação Superior, realizado entre 2010 e 2015 pelo Instituto Nacional de Estudos e Pesquisas Educacionais Anísio Teixeira, o INEP, considerou 670 instituições de Ensino Superior. Observou-se que mais de $80,74 \%$ delas possuíam 541 alunos com deficiência auditiva ${ }^{4}$ e em $48,36 \%$ havia 324 alunos surdos profundos e, ainda, em $7,16 \%$ estavam matriculados 48 estudantes surdo-cegos (ESDRAS; GALASSO, 2017, p. 16).

Em relação ao censo anterior, verificou-se o aumento de $20,76 \%$ de ingresso de deficientes auditivos no Ensino Superior brasileiro; de 41,2\%, em relação aos surdoscegos; e de $35 \%$, no que concerne aos surdos profundos (Idem, ibidem, p. 17). Sobre o ingresso de surdos, para Esdras e Galasso, "tal

\footnotetext{
4 Esdras e Galasso distinguem em sua obra (2017), ao falarem sobre o censo, surdos de deficientes auditivos, considerando os primeiros como portadores de surdez profunda e falantes de Libras como L1. Apenas por esta razão, utilizamos nesse trecho do trabalho o termo "deficiência auditiva". Não concordamos com ele, por partilharmos da percepção cultural da surdez, fora do espectro da deficiência, como anteriormente afirmado.
} 
crescimento pode ser reflexo de diversas políticas públicas voltadas aos surdos nas últimas duas décadas" (Idem, ibidem, p. 17).

Se por um lado ampliou-se enormemente a entrada de surdos nas universidades brasileiras, por outro a garantia de sua permanência e da qualidade de sua formação ainda imiscui-se em desafios múltiplos, como a presença de intérpretes qualificados e aptos a interpretar aulas com conteúdos complexos, como pertinente às da Educação Superior; a produção de materiais específicos para os surdos em Libras, sobretudo os que traduzam obras seminais da área de Letras - inclusive as que versam sobre temáticas dos estudos de Libras e de Literatura Surda; e a adequação dos espaços físicos à acessibilidade dos surdos, por exemplo.

Destacamos aqui um desafio capital para o Ensino Superior de surdos: o reconhecimento da Libras como língua, o que implica, obviamente, em questões relativas a sua validade como língua acadêmica. Percebe-se uma teia de fricções entre concepções distintas acerca do conhecimento produzido nas universidades, dentro da qual a Libras, como língua minoritária, enfrenta traços de uma tradição centrada em um pensamento que privilegia a escrita e a oralidade como modos privilegiados nos processos de construção do saber e da expressão reflexiva.

\section{CONCEPÇÕES SOBRE LETRAMENTOS, LITERATURA E ENSINO DE SURDOS}

Frente ao cenário que delineamos, propomo-nos a pensar o lugar ocupado pelo ensino de literatura para surdos, muito especialmente nos currículos dos cursos de licenciaturas em Letras-Libras. Nosso objetivo central neste texto não é o de discutir aspectos metodológicos do ensino de literatura, mas o de refletir sobre as formas pelas quais se organizam aspectos dos letramentos literários de surdos, considerando-os no âmbito dos Novos Estudos de Letramentos (STREET, 2014).

Isso nos leva a reconhecer, como propõe Brian Street, um modelo ideológico de letramento, percebendo os letramentos como plurais e intrinsecamente vinculados a contextos culturais e sociais, em uma perspectiva sociolinguística, em oposição a um modelo autônomo, que 
entende o Letramento - na percepção de Street (2014), com L maiúsculo como um padrão único, divorciado dos referidos contextos e reduzido a uma habilidade técnica.

Ao reconhecermos os letramentos pela dimensão ideológica proposta por Street (2014), compreendemos os eventos e práticas de letramentos dos alunos surdos como indissociáveis dos contextos culturais e linguísticos dos quais participam, diretamente conexos aos processos de construção de suas identidades. No que toca especificamente aos seus letramentos literários, pretendemos pensá-los em suas relações tanto com a produção literária surda, como com o ensino de literatura, e analisá-los face aos discursos e práticas de identidade e de poder, que a eles se ligam.

Acreditamos que tais discursos e práticas são vinculados a concepções diferentes e, por vezes, conflitantes, sobre os conceitos de conhecimento, texto e literatura. Assim, a universidade, entendida por nós como um espaço privilegiado de produção de saberes, apresenta-se como uma arena onde perpassam discursos e práticas vinculados a uma noção predominante do conhecimento como prática grafocêntrica e oral, que institucionaliza situações de poder e de exclusão.

Tal situação radicaliza-se dentro das dinâmicas presentes no Ensino Superior de surdos, por estarem ligadas a uma minoria cultural e linguística, cuja língua dominante é a Libras (Língua Brasileira de Sinais).

No caso do ensino de literatura, percebemos dentro do espaço universitário, ao considerarmos como balizas a produção de pesquisa e os programas de ensino, o predomínio de uma perspectiva tradicional no que toca ao conceito de obra literária - embora já haja vozes que a contraponham, como a que compreende a inespecificidade como uma característica da obra literária na contemporaneidade (GARRAMUÑO, 2014).

A perspectiva tradicional concebe o texto literário como indissociável da palavra escrita. Essa concepção retira dos povos ágrafos o direito à literatura, para usarmos a expressão do pesquisador brasileiro Antonio Candido, título de seu texto homônimo, no qual defende como bem inalienável o acesso do ser humano à obra literária. 
Ela se situa historicamente em diálogo com a própria origem do termo literatura, oriundo da palavra latina littera, ou seja, letra. O centramento etmológico da literatura na grafia alimenta o consenso de que a literatura é uma arte verbal, presente em diversas concepções apresentadas sobre 0 literário.

Nesse sentido, Todorov (1978, p. 15) endossa tal proposição ao afirmar que a arte se categoriza a partir de como se materializa; assim, "a literatura é imitação pela linguagem, tal como a pintura é imitação pela imagem".

De que maneira a afirmação da literatura como arte verbal excluiria certas produções em língua de sinais como literárias? Nossa resposta é: de nenhuma. Essa compreensão não retira da Libras a condição de produzir literatura, uma vez que, embora nela predomine a modalidade visual e espacial5, ela é reconhecidamente uma língua, logo, é verbal.

Isso posto, gostaríamos de sublinhar as concepções de literatura propostas por dois pesquisadores contemporâneos, Terry Eagleton (2001) e Jonathan Culler (1997). Ambos rechaçam a possibilidade de pensar o conceito de literatura como ontológico e destacam seu caráter social e histórico, portanto dinâmico e plural, em movimento contínuo de releituras. A concepção de literatura, logo, perpassa juízos de valores organizados por grupos sociais reconhecidos como competentes para emitirem opiniões e endossarem discursos acerca da natureza do literário e de suas expressões.

Quando se pensa em uma concepção de literatura como arte verbal que a restringe ao terreno da produção escrita, incorre-se em um preconceito, que abarca o não reconhecimento das línguas de sinais como línguas. Perpetua-se também o paradigma que relaciona o conceito de texto ao modo escrito e ao meio impresso, que considera o texto somente como o que é grafado. Nesse sentido, é importante pensar no conceito de texto em um sentido amplo (JEWITT, 2008), de maneira a entendê-lo através de outros modos, como o visual e o visoespacial.

\footnotetext{
5 Ver nota 2.
} 
O fato é que, como percebe Kress (2003), a partir da virada do século XX para o século XXI, há uma mudança radical de paradigma, quando a escrita, na condição de modo, e o livro, de meio, perdem o seu domínio como instrumentos privilegiados de conhecimento; passa-se, então, ao predomínio da imagem e da tela, enquanto modo e meio, respectivamente.

Portanto, a partir de dois pilares, balizamos a existência de uma literatura em língua de sinais: a perspectiva contemporânea do conceito de texto e a compreensão da Libras como língua que produz, pela modalidade visual e espacial, linguagem verbal. Em Libras, a inscrição do corpus literário não se dá no papel, mas no próprio corpo, que se aventura como lugar da enunciação estética.

\section{CONSIDERAÇÕES SOBRE O LUGAR DO ENSINO DE LITERATURA NOS CURRÍCULOS DOS CURSOS DE LETRAS-LIBRAS}

Se dentro dos cursos de Letras ainda causa estranhamento a presença de programas que considerem a literatura em língua de sinais, tal postura concerne a leituras muito tradicionais dos conceitos de texto e de literatura, assim como à marcação de territórios simbólicos de poder, que constroem discursos excludentes em relação à diferença cultural, percebida por nós em concordância com a postulação de Bhabha, isto é como "um processo de significação através do qual enunciados sobre ou em uma cultura diferenciam, discriminam e autorizam a produção de campos de força, referência, aplicabilidade e capacidade" (BHABHA, 1994, p.34).

Compreende-se nesse contexto que novas concepções sobre conhecimento - e a noção de uma literatura em língua de sinais diz respeito a isto - desloquem poderes que sustentam a continuidade de determinados grupos, o que os levam a uma postura endógena, capaz de contribuir para a marginalização das minorias linguísticas e culturais.

A análise dos dados coletados (através de observação, entrevistas e depoimentos dos já referidos graduandos surdos de cursos de Licenciatura em Letras-Libras de uma universidade brasileira) em nossa pesquisa permitiunos perceber o alcance da visão tradicional que associa a literatura à 
escrita, e a uma perspectiva canônica, alcançando grupos de estudantes surdos. Foi notado que as experiências dos letramentos literários de surdos estão circundadas tanto pelo grafocentrismo acadêmico quanto pelos discursos essencialistas acerca das identidades surdas e de suas relações com a língua portuguesa como signo de uma alteridade, cuja contraposição fortaleceria a construção identitária surda, atrelada à condição dos grupos surdos como minorias linguísticas.

É interessante atrelar essas percepções presentes nas falas dos alunos ao fato de encontrar-se nos currículos escolares das escolas bilíngues da Educação Básica um silenciamento em relação ao ensino de literatura, o qual não é expressamente previsto nos programas das disciplinas (PEREIRA; ABRAHÃO, 2015). Se nos cursos superiores de Letras-Libras o lugar da literatura ainda é periférico na organização curricular (PEREIRA; ABRAHÃO, 2015), isto pode ser inscrito em um continuum iniciado desde os primeiros anos da educação formal.

Dentro das comunidades surdas, segundo depoimentos dos mesmos graduandos, esse posicionamento explica-se por uma concepção partilhada entre muitos surdos, a saber, o da ideia de literatura como uma instância necessariamente ligada à língua portuguesa. Nos depoimentos coletados sobre o conceito de literatura, no momento inicial da pesquisa, no primeiro semestre de 2017, todos os alunos relacionaram a experiência da literatura à língua portuguesa, em torno de dois padrões de resposta, que se interseccionam.

O primeiro afirmava a literatura como restrita a instrumento de ensino da língua portuguesa como segundo língua; o segundo alocava a noção geral de literatura no domínio da escrita em língua portuguesa, associado por parcelas das comunidades surdas a processos de opressão e intolerância às identidades e culturas surdas, em tensão aos usos da Libras. Percebemos, ainda, que ao entrarem na licenciatura em Letras-Libras, muitos graduandos surdos não compreendiam o sentido de estudar disciplinas de Literatura, exceto as voltadas para a Literatura Surda. 
Em nossa pesquisa, compreendemos que esse posicionamento vem de uma história escolar que tende, como falamos, a alijar o ensino de literatura dos programas escolares da Educação Básica voltados para os surdos. Vem também da ideia de que os cursos de Letras-Libras devem restringir seu programa ao estudo da Língua Brasileira de Sinais e de manifestações literárias surdas, por vezes abordadas em leituras impressionistas.

Todavia, no decorrer de nossa pesquisa, muitos dos graduandos surdos tenderam a mudar a sua percepção inicial e se mostraram entusiasmados com os estudos literários a partir da ampliação de sua visão sobre o conceito de Literatura, o que implicou no reconhecimento do prazer estético e do desenvolvimento da capacidade crítica proporcionada pela literatura. Foi despertada uma consciência em muitos dos estudantes pesquisados acerca da expressão estética em línguas de sinais, que se atrelou a reflexões sobre a cultura e a identidade surda.

Relataremos uma dessas experiências, vivida por uma graduanda surda, do terceiro período do curso de Licenciatura em Letras-Libras. "Parece que ele conhece toda a minha vida", relatou a aluna, em depoimento. $O$ termo "Ele" é uma anáfora para Fernando Pessoa, em conversa colhida em uma aula que retomava conversas de duas aulas anteriores, nas quais a vida de Pessoa e seus poemas, traduzidos em Libras, foram apresentados'.

$\mathrm{Na}$ terceira aula, a aluna apresentou os resultados de uma pesquisa na qual foi orientada a escolher como objeto de análise um poema de Fernando Pessoa e uma pintura, ambos a sua escolha, com o fim de estabelecer diálogos entre a linguagem poética da obra de Pessoa e o texto

\footnotetext{
${ }^{6}$ Nas aulas, foram apresentadas e discutidas poesias de Pessoa traduzidas para Libras, como "Poema em Linha Reta" (Álvaro de Campos) e "O encoberto", de Mensagem, além de "Mar português", também de Mensagem, "Aniversário" (Álvaro de Campos) e "Para ser grande, sê inteiro" (Ricardo Reis). Embora o objetivo deste artigo não seja a orientação metodológica ou o relato de experiência, vale reportar que se buscou nas aulas uma abordagem multimodal e intertextual, instigando o processo reflexivo sobre possíveis diálogos entre os textos poéticos em Libras e imagens trazidas pelos alunos, além da ressignificação dos poemas, pela criação de textos em Libras. Textos visuais como as capas da revista Orpheu, o retrato de Fernando Pessoa por Almada Negreiros e os desenhos dos heterônimos por Pessoa também foram objetos de reflexão e de estudo, endossando a perspectiva dialógica pretendida, entre textos de múltiplos modos.
} 
visual escolhido. A aluna apresentou uma pintura de estilo impressionista, de autoria desconhecida; a tela mostrava em pinceladas fortes e difusas a imagem de uma mulher no campo. O poema escolhido, em língua portuguesa, foi "É um campo verde e vasto". A partir do signo da solidão, apontado por ela como presente no texto visual da pintura e no texto escrito em língua portuguesa, a discente relacionou as imagens difusas da tela à predominância de sentidos que convergiam para a ideia de incerteza no poema.

Notou-se em sua apresentação o estranhamento estético, para citarmos o conceito de Chklovski ${ }^{7}$ (1973), produzido pela recepção da arte poética de Pessoa. Esta the imprimiu uma sensação ápora, pois a consciência da distância do momento de enunciação da obra tensionavase com o pathos, a empatia que ela desenvolve como receptora, que projeta o reconhecimento de suas experiências na obra.

Essa perspectiva vai ao encontro de uma percepção que nos é muito cara, a saber, a labilidade das fronteiras entre o espaço formal acadêmico e as vivências dos alunos fora dele (JEWITT, 2008). Concebemos que haja um espaço de interação intenso entre as duas instâncias, que se retroalimentam; isto significa, sobretudo, acolher as vivências históricas, culturais e sociais dos sujeitos que dele participam, e pensar suas interações e tensões, refletindo e respeitando a diferença cultural (BABHA, 2010).

Neste sentido, cabe também compreender novos delineamentos no que tange às experiências e produções literárias relacionadas às comunidades surdas. Isso permite conhecer e pensar sobre objetos e práticas estéticas inovadoras, que dizem respeito não apenas às comunidades surdas, mas a todos que tenham a arte como ponto de interesse.

Aqui, recuperamos a nossa fala anterior, sobre a porosidade entre a sala de aula e o espaço externo a ela: é preciso, ao trabalharmos com os

\footnotetext{
7 Chklovski, em seu artigo "Arte como procedimento estético", aborda o estranhamento provocado pela obra de arte, capaz de levar o sujeito à ruptura do automatismo perceptivo.
} 
letramentos literários de surdos, que o coloquemos como sujeitos, e não como meros receptores de informação.

É importante tanto ampliar a percepção acerca dos conceitos de texto e de literatura, como instâncias que se situam para além da modalidade escrita, como dar visibilidade a formas poéticas produzidas em Libras, muitas delas inovadoras, trazendo para o espaço acadêmico a produção literária que já circula nas comunidades surdas.

Assim, propõe-se que os cursos de Letras-Libras abram espaço para que os graduandos surdos tenham acesso a um repertório cultural e literário universal, a ser reconstruído em novas produções em Libras. O direito a verticalizar reflexões conceituais no âmbito da literatura, pelo diapasão da Libras, deve-lhe ser dado.

Volto nesse ponto ao relato sobre a aluna supracitada, que anunciou "parece que ele conhecia toda a minha vida" e o seu espanto, vindo da empatia que encontrou, como leitora, com a obra de um poeta que até então desconhecia - um homem de país, língua e cultura diversos da dela. Como explicar que aquele estranho pudesse compreender seus sentimentos e experiências, senão pela força da literatura como potência reflexiva, capaz de estabelecer diálogos sensiveis, para além do tempo e do espaço?

O espanto da estudante diante de uma voz ficcional complexa como a de Pessoa, que organiza lugares de reconhecimento para ela como leitora, ancora-se no estranhamento estético, situa-se na capacidade da literatura quebrar a percepção automática das dimensões da realidade que nos alcança. Também revela a sua compreensão da poesia como experiência ligada à reflexão sobre a própria subjetividade, como uma partilha de vivências em simbiose: a concreta e a simbólica. Espanta-se a graduanda diante da obra de Pessoa por saber-se revelada como sujeito pelo olhar poético, por essa forma de ver o mundo capaz de adivinhá-la sem conhecê-la, porque tem o poder de levar o sujeito leitor a estas revelações sobre si e sobre a vida que o cerca.

A potência do impacto da poesia de Pessoa na discente a leva a construir a partir do lugar de leitora um esteio para a sua face como 
criadora, o que a levou a anunciar, na aula, que apresentaria um poema em Libras sobre Fernando Pessoa e seus poemas. Na criação apresentada, ela estabeleceu relações intertextuais e intersemióticas, dialogou com a obra de Pessoa e criou a partir de um poema escrito em língua portuguesa um texto em três dimensões, na modalidade visual e espacial pertinente à Libras.

Recriou com sinais, expressões faciais, classificadores ${ }^{8}$ e movimentos um texto fora do suporte escrito, em três dimensões- um texto que se vê no espaço, um corpus que se anuncia e se enuncia em um corpo em movimento. Apresenta-se como enunciado desse texto e, ao mesmo, tempo como sujeito lírico, que assume ao criar e incorporar Fernando Pessoa como personagem. O poema em Libras enuncia o cotidiano do poeta, sua ida ao café, suas inspirações e a criação de seus poemas, ações e sentidos traduzidos pela aluna esteticamente na língua de sinais brasileira.

Seu protagonismo na criação do poema, em intertexto com a poesia de Fernando Pessoa, mostra-nos um contexto de hibridismo cultural, presente no cenário mundial, e que deve ser assumido nas aulas de literatura. Em uma perspectiva mais ampla, percebemos entre o grupo de alunos aqui pesquisado que o fato de levá-los a conhecer produções poéticas de outras línguas e culturas não os conduziu a um processo de aculturação; ao contrário, o trabalho com textos poéticos de outras paisagens culturais estimulou o seu olhar criativo e ampliou a sua percepção de mundo, catalisando criações intertextuais em Libras. Todavia, considerou-se a dificuldade de muitos surdos lerem textos complexos em língua portuguesa quando esta é a sua segunda língua. Seria, por isto, importante o aumento de traduções literárias para a língua de sinais - que existem, mas são ainda muito poucas. Ainda assim, podemos concluir que os surdos têm direito à literatura universal, e isto não implica seu afastamento do conhecimento da literatura em língua de sinais; ao contrário, os movimentos de leitura literária

8 Classificadores são elementos da Língua de Sinais que atuam como descritivos, simulando sons, cheiros, objetos, seres e formas gerais. 
de artefatos provenientes de culturas distintas são dialógicos e se retroalimentam.

Pensar a ideia de uma literatura pura, ligada à ideia de identidade estável, não se sustenta na pós-modernidade, como demonstra Hall (2005); as identidades são plurais e instáveis. Ao tomarmos como esteio teórico o pensamento de Canclini (2006), percebemos a impossibilidade de pensar a literatura surda bem como quaisquer outras manifestações estéticas pela chave da pureza cultural.

Vivemos em um mundo em que culturas diferentes circulam e encontram-se, promovendo práticas multiculturais e transculturais. Concordamos com a perspectiva de Canclini, ao afirmar as culturas na pósmodernidade como de fronteiras, resultantes do contato com as alteridades e dos deslocamentos dos bens simbólicos. Nesse sentido, tanto a literatura surda irá deslocar e reapropriar bens simbólicos vindos de outras culturas, como o mesmo processo acontecerá por parte de outros contextos culturais em relação ao dela'.

Logo, cremos que seja mais profícuo franquear o acesso dos estudantes surdos a repertórios literários vindos de culturas múltiplas, a fim de proporcionar uma leitura analítica e comparada com a produção proveniente da cultura surda.

Ainda que consideremos fundamental que a literatura surda em língua de sinais assuma o centro no processo formal de educação literária de sujeitos surdos que se identificam como falantes de Libras como primeira língua, acreditamos que a circulação de formas culturais híbridas, que se apresenta na pós-modernidade fora do espaço escolar, não possa ser ignorada. De tal forma, ao entrar em contato pela primeira vez com a poesia de Fernando Pessoa, a aluna já referida não abandonou a sua

\footnotetext{
9 Como exemplo, o jornal O Globo, em 14/04/2018, na página de uma crítica de Bolívar Torres sobre um livro de auto-ajuda, sem relação com a cultura surda, foi inserida a fotografia de mãos a fazer em datilologia a última palavra do título da obra. No mesmo sentido, nota-se o deslocamento da língua de sinais americana como bem simbólico no filme 'A Forma da Água' (2018), de Guillermo Del Toro, pois a ASL é usada por personagens que não se identificam, necessariamente, com comunidades surdas.
} 
identidade surda ou sentiu-se oprimida por se tratar de repertório produzido originalmente em sua segunda língua.

Em vista disso, concordamos com a ideia de Eagleton (2001) de que toda leitura é um processo de reescritura. Por isso, apontamos que a estudante, ao tomar para si a posição de co-criadora dos poemas de Fernando Pessoa que lera e ao imprimir a eles sua leitura, mobilizou uma nova criação estética, a partir dos elementos culturais e de identidades que ela carregava, de seu horizonte de expectativas. Ela abandonou a passividade da recepção e transportou-se para o protagonismo da condição de autoria, ao mostrar uma criação literária em sua língua, a Libras, em performance, em uma organização estética que tem no corpo o seu corpus.

\section{O CORPO COMO CORPUS - NOVAS EXPERIÊNCIAS NA LITERATURA SURDA, EM LÍNGUA DE SINAIS}

Podemos considerar o texto literário em Libras como performance por ele envolver a tríade indissociável corpo/movimento/arte em seu processo de comunicação. É uma forma de arte que se constrói no corpo em movimento, que pode acontecer em quaisquer momentos e lugares, em uma condição de não repetição, a não ser quando registrada em vídeo.

Enquanto performance, a literatura em língua de sinais apresenta-se como uma estética do corpo inserido em um contexto espaço-temporal, que coloca no centro a visualidade e o movimento na organização de sua linguagem literária (ROSE, 2006). É uma literatura que envolve texto (geralmente, em Libras), imagem e movimento, indo ao encontro da ideia de experimentação e imprecisão das definições estéticas presentes na literatura contemporânea (GARRAMUÑO, 2014).

O interesse dos alunos que contribuíram para esta pesquisa pela literatura foi marcado por declarações como a de um graduando que nos revelou, em Libras: "eu fico feliz por aprender literatura. Porque na escola não ensinam literatura para o surdo e eu não aprendi. Mas agora eu posso ensinar aos meus alunos". 
Esse interesse dos graduandos, ao descobrirem relações possíveis com a literatura, para além do âmbito instrumental do ensino de língua, levou-nos a pesquisar categorias da literatura surda - aqui concebida como tangente a temas da cultura surda quanto à produção em língua de sinais - que já eram conhecidos e circulavam nas comunidades surdas, mas que logravam pouca atenção das pesquisas acadêmicas no Brasil, em geral.

Apontamos três categorias poéticas, que se tornaram objetos de estudo: a Poesia A-Z, o Slam Surdo e a Visual Vernacular. As três categorias encaixam-se em nossa concepção da literatura surda como performance. A partir desse entendimento, concordamos com Sutton-Spence e Kaneko (2016) que compreendem a literatura em língua de sinais muito mais como um processo do que como um objeto materializado. A literatura surda é performance porque é ação, é produção em movimento. Inclui a presença de seu enunciador, que pode durante o processo da narração incorporar concomitantemente o papel de narrador e o dos personagens.

O processo de narração da literatura surda pode ser comparado ao conceito de narrador de Walter Benjamin. Em "O narrador", Benjamin fala sobre duas categorias de narradores, que vincula a processos históricos, sociais e econômicos distintos: o narrador oral, o contador de histórias das sociedades artesanais, e o narrador do romance, vinculado à sociedade industrial, voz desintegrada da presença, uma vez que está escrita e inscrita em definitivo na folha de papel.

Benjamin vincula o narrador oral a uma sociedade fundada na experiência coletiva e em um tempo marcado pela natureza, que dá aos sujeitos a oportunidade de sonhar e de partilhar as suas vivências. O narrador oral está presente por inteiro e sua narrativa abre-se para as indagações, intervenções e modificações surgidas em sua interação com a audiência. Ele se apresenta por completo, corpo - movimentos, gestos, olhares - e alma. Daí a sua comparação com o oleiro. Como o oleiro - que em seu trabalho artesanal deixa as suas impressões digitais no objeto de barro por ele criado é o narrador oral, que imprime sua identidade e leitura de mundo na contação de histórias. 
Tal qual o narrador oral lido por Benjamin, o narrador da literatura em língua de sinais está presente, em seu corpo e em sua alma, imprimindo sua identidade e leitura de mundo nas formas de contar suas histórias, uma vez que ele as constrói como performance, como um exercício estético do agora, da sua presença.

É importante destacar: embora a analogia entre o narrador oral benjamininano e o narrador em língua de sinais venha de uma leitura nossa, a visão comparada entre produções orais e em língua de sinais já é objeto de estudo há algum tempo, sobretudo nas pesquisas empreendidas por estudiosos americanos.

Assim, Bauman, Nelson e Rose (2006) sinalizam como pontos de convergência entre a literatura oral e a literatura surda a contraposição de ambas às formas tradicionais escritas e o fato de seus processos de transmissão serem feitos face a face, sendo a presença e a transmissão geracional valores e práticas relevantes nos processos de organização literária para as comunidades surdas falantes de línguas de sinais. Evidenciam que essa relação nada tem a ver com a ideia de oralismo, ou oralização, mas unicamente "às similaridades entre a literatura em língua de sinais e a literatura oral". Nesse sentido, é interessante notar que o professor surdo Ben Bahan lecionou a disciplina "Tradições orais na comunidade surda" na Universidade Gallaudet, nos Estados Unidos, voltada totalmente para o ensino superior de surdos.

Portanto, a literatura em Libras, postulamos, é performática e híbrida, em vários sentidos. Como performance, ela é híbrida em sua estrutura estética, na fronteira entre o cinema, a dança e o teatro. Como narrativa, ela hibridiza as enunciações presentes nos processos de narração; e, como veremos, ela também é híbrida culturalmente como modalidade artística aberta à apropriação e à transformação de formas estéticas e discursivas plurais. Para demonstrá-lo, faremos um breve mapeamento das três categorias literárias supracitadas, com o foco em suas formas de organização poética. 
A primeira categoria sobre a qual nos debruçaremos será a Visual Vernacular. Apesar do nome, não apresenta relação alguma com a palavra escrita. Ao contrário, a Visual Vernacular caracteriza-se como um misto de performance teatral, poesia e mímica. Ela pode acontecer em um espaço físico ou ser apresentada na forma de registro em vídeo. Dos dois jeitos, prevê movimentos contínuos e gradações de velocidade, que imprimirão significações e ritmo à narrativa.

Nas apresentações ao vivo, a Visual Vernacular constrói um espaço simbólico e personagens que desenvolverão nele uma história através do uso de sinais, classificadores e expressões visuais. O narrador assume, ao mesmo tempo, a enunciação e a representação do espaço/cenário e das personagens.

Há uma convergência entre relatos de surdos brasileiros e americanos sobre a origem da Visual Vernacular em seus países. Os americanos contam que a Visual Vernacular nasceu com os relatos dos surdos sobre as histórias contadas nos cinemas. No Brasil, a comunidade surda conta que a Visual Vernacular teve a sua origem em um momento em que o Instituto Nacional de Educação de Surdos - o INES - tinha alunos internos pobres. Seus colegas em melhores condições financeiras iam ao cinema, geralmente para verem filmes de Faroeste, e ao retornarem ao INES Ihes contavam o que haviam visto nos filmes.

Outra versão para o surgimento da Visual Vernacular situa a sua origem como uma criação do artista Bernard Bragg, falecido em 2018. Ele conta que aceitou o convite de Marcel Marceau para estudar mímica em Paris, e a partir deste curso desenvolveu uma técnica de performance que batizou de VV - Visual Vernacular. Na verdade, Bragg disse que a VV é uma forma de mímica, mas fora da estrutura da mímica tradicional, pois recorta na performance um espaço menor e usa procedimentos da linguagem cinematográfica, como a sobreposição de imagens, a aceleração ou a diminuição da velocidade do filme e o emprego de imagens borradas.

É importante notar que com o surgimento das novas tecnologias e das redes sociais, alinhadas aos processos de globalização do século XXI, outros 
artistas passam a produzir e a divulgar a Visual Vernacular em vídeo, o que insere muitas das criações da Visual Vernacular na contemporaneidade dentro de uma compreensão mostrada por pesquisas como as de Bauman (2006) que apontam o intenso e profícuo diálogo entre a literatura de língua de sinais e a linguagem cinematográfica.

Para Bauman, as formas artísticas em língua de sinais criam imagens em movimento capazes de emularem técnicas usadas em filmes. O pesquisador considera as produções em Visual Vernacular gravadas em vídeo como performances cinematográficas, pois o artista criador além de ser o enunciador (sinalizador, na proposição de Bauman) e incorporar posições de narrador, personagem e cenário, também filma e edita a obra.

Ao continuar o nosso mapeamento, seguimos para o Slam Surdo. Forma poética híbrida, tem como ponto de partida o movimento artístico do Slam Poetry, surgido nos Estados Unidos, na década de oitenta. O Slam Poetry caracteriza-se como uma poesia de performance que mistura a poesia falada e movimentos rítmicos corporais, com base nas apresentações de Rythm and Poetry (RAP).

O Slam não visa à publicação impressa, mas a apresentações que podem ser individuais ou em forma de "batalhas", isto é, de competição entre poetas, assumindo a forma de performance, em suas características de arte que se constrói através de características como a espontaneidade, a presença, a ação, o improviso e a comunicação através do corpo.

Aqui, retomamos a ideia de Canclini acerca do conceito de hibridismo cultural em um contexto atrelado às culturas de fronteiras e aos deslocamentos dos bens simbólicos, pelo fato do Slam Surdo, que no Brasil chega nos anos 2000, apropriar-se do Slam Poetry e reelaborar a sua proposta pela perspectiva de elementos pertinentes às culturas surdas, pois o Slam Surdo caracteriza-se como uma expressão literária situada em uma dinâmica de performance, a partir de um encontro entre surdos e ouvintes.

Surdos e ouvintes formam pares poéticos e organizam o slam surdo em uma dinâmica de enunciação simultânea do texto literário, pareando oralidade e a sinalização. Em Língua Portuguesa e Libras, compõem 
narrativas apresentadas em performances que mesclam dança, teatro, narrativa e poesia e abordam pensamentos e experiências ligados às identidades surdas, em tom de denúncia e crítica ao preconceito e à intolerância. Ao mesmo tempo, organizam-se como um artefato produzido na interseção de fronteiras culturais e linguísticas propositalmente lábeis, que destacam processos de interação.

Há no jogo cênico do slam surdo estratégias de enunciação organizadas através de movimentos de paralelismos, espelhamentos e inversões realizados pelos pares falantes em Libras e língua portuguesa, mostrando a sincronia entre o narrador ouvinte e surdo. Logo, há no Slam Surdo uma manifestação estética na qual elementos dramáticos e poéticos convertem-se em textos bilíngues, em um encontro dialógico entre elementos das culturas surdas e não surdas, que não leva a um apagamento ou a uma homogeneização cultural, tampouco a embates valorativos.

Ao contrário, o Slam Surdo permite o trânsito fluido de culturas, assumindo a heterogeneidade e o respeito às alteridades, ao passo que também dá visibilidade à literatura surda, por atingir públicos de outros espectros que não apenas os das comunidades surdas, divulgando-a como experiência estética para um público mais amplo.

Por fim, como manifestação da poética surda contemporânea, a Poesia de A a Z caracteriza-se como uma performance de desafio, a partir do que poderíamos chamar de uma literatura de limites. Nesse sentido, ela pode ser comparada aos exercícios literários do movimento europeu de escrita criativa OULIPO, embora não haja registro de que isto seja um diálogo proposital.

Ao contrário, Rutheford (1993 apud SUTTON-SPENCE; KANENO) sugere que as manifestações de Poesia de $A$ a Z , chamada $A B C$ stories nos Estados Unidos, são reportadas, pelo menos, desde 1900, portanto bem antes da OULIPO surgir, o que nos leva a compreender que apesar da poesia de $\mathrm{A}$ a $\mathrm{Z}$ ter uma origem situada há mais de 100 anos, a sua consecução como exercício poético de desafio hoje pode apresentar-se em configurações distintas. 
O fato da poesia de A a Z na contemporaneidade apresentar-se de forma distinta deve-se à emergência e difusão em massa das novas tecnologias de comunicação e de informação, que possibilitaram - como às performances em Visual Vernacular - uma constituição intermidiática que Ihe imprimiram uma organização poética distinta, em sua interface com a linguagem cinematográfica, capaz, por exemplo, de disponibilizar recursos como a inserção de imagens na tela, par e passo à performance poética.

A proposta artística da Poesia de A a Z consiste no desafio de performar para cada letra do alfabeto datilológico, em sequência, uma imagem, sentimento ou objeto relacionados a um tema escolhido. Essas imagens precisam ser construídas através de sinais ou classificadores associados às formas de cada uma das letras do alfabeto dactilológico. Há, pois, nessa forma artística um sentido de hibridismo, ao justapor o alfabeto à sinalização.

Concordamos, logo, com Rutherford (2006) quando esta percebe as $A B C$ stories como narrativas que fazem a mediação entre dois pólos de identidade linguística. No pólo externo, estaria a alteridade, no exercício de controle da língua inglesa; do outro a identidade, na língua interna à identidade surda, a de sinais.

\section{POR UM CURRÍCULO ALINHADO A NOVAS EXPERIÊNCIAS}

A poesia de $A$ a $Z$ junto aos dois outros movimentos da literatura contemporânea em língua de sinais que circulam nas comunidades surdas brasileiras - Slam Surdo e Visual Vernacular - estão presentes, sobretudo em São Paulo, Rio de Janeiro e Paraná. Apresentam traços pertinentes a experimentações artísticas na contemporaneidade produzidas por falantes de línguas orais, como o que Garramuño (2016) compreende como a inespecificidade estética, a transcendência da escrita como padrão único de letramento literário, a elaboração de textos multimodais, a performance e a intermidialidade.

Como afirmaram Bauman, Nelson e Rose (2006), a posição marginal ocupada pela literatura em línguas de sinais acabou por levá-la a um 
processo de experimentação estética extremo. Nós o afirmamos como um processo de profunda criatividade, que se aguçou especialmente a partir do início dos anos 2000, com a difusão em maior escala das novas tecnologias de informação e de comunicação, responsáveis pelo acesso de um grupo maior de artistas ao uso de recursos tecnológicos mais complexos e de composições intermidiáticas.

A liberdade dada a esse processo, em vista da posição fora da centralidade, que construiu uma literatura potente e rica, inscreveu-se e inscreve-se em um cenário de hibridismo cultural, com elementos estéticos inovadores, expressos em uma língua tridimensional, visual e espacial, em estratégias performáticas que dizem respeito às comunidades surdas e também a todos os demais interessados por arte e literatura.

É fundamental abrir espaço nos currículos escolares dos cursos de Letras-Libras para essas novas experiências literárias que já circulam nas comunidades surdas, atentando à porosidade entre os espaços da sala de aula e fora dela como lócus de produção de saberes, tal como sugere Jewitt. Isso implica em compreender a Libras como uma língua e a literatura como um conceito complexo e situado para além do texto escrito, presente nas produções em Libras, nas quais o corpo emerge como o corpus literário.

Como postulamos, nos textos artísticos em Libras é o corpo o lugar de inscrição e de produção de sentidos simbólicos, em um jogo literário tridimensional que se alinha à inespecificidade estética da literatura na pósmodernidade, abrigando em jogos de linguagem poética tridimensionais elementos intermidiáticos, como a Visual Vernacular, de tradições de grupos surdos, como a poesia de $A$ a $Z$, e de encontros multiculturais e bilíngues, como o Slam Surdo.

Portanto, propõe-se aqui, a partir dos questionamentos lançados e das reflexões estabelecidas, uma luz acerca da necessidade de pensar sobre novos delineamentos curriculares nos cursos de Letras-Libras, ampliando o espaço ocupado pelas disciplinas de literatura. Acreditamos que para tanto seja preciso colocar em xeque orientações que considerem a literatura 
como mero instrumento de ensino de línguas, ou circunscrita ao modo da escrita em língua portuguesa.

Pensar sobre o local tímido ocupado pelas disciplinas de literatura nos cursos de Letras-Libras é refletir também sobre quais concepções embasam esta escolha. Impõe-se a discussão sobre concepções de texto e literatura que transcendam o modo escrito e que compreendam, para além do Letramento acadêmico padrão, os letramentos em Libras.

Faz-se necessário que se considere como objeto de reflexão dos graduandos de Letras-Libras não apenas narrativas infantis adaptadas dos contos de fadas e piadas, mas também textos contemporâneos em Libras, produzidos por adultos e com tessituras poéticas e reflexões mais complexas. São textos que já circulam nas comunidades surdas e que ainda procuram espaços nos currículos acadêmicos.

Por fim, acenamos para a necessidade de ampliarmos o acesso dos graduandos surdos dos cursos de Letras-Libras a um currículo no qual o ensino de literatura tenha, além de relevância, um design que abarque experiências de letramentos literários advindas de produções multimodais com textos visuais, escritos e viso-espaciais - e de um prisma multicultural, capaz de fomentar diálogos entre as culturas surdas e outras culturas e de proporcionar vivências que apresentem a obra literária como um elemento de fruição estética e de reflexão.

\section{REFERÊNCIAS}

BABHA, H. The Location of Culture. London: Routledge, 1994.

BAUMAN, D.; NELSON, J. E ROSE, H. Signing the Body Poetic: Essays on American Sign Language Literature. Los Angeles: University of California Press, 2006.

BENJAMIN, W. O narrador. In: Magia e técnica, arte e política. São Paulo: Brasiliense, 1994.

BOTELHO, P. Linguagem e Letramento na Educação dos Surdos: ideologias e práticas pedagógicas. Belo Horizonte: Editora Autêntica, 2002. 
BRASIL. Lei n.10.436/2002. Disponível em: <http//:planalto.gov.br>. Acesso em: 10 fev. 2015.

BRASIL. Decreto 5.626 de 22 de dezembro de 2005. Regulamenta a Lei no 10.436, de 24 de abril de 2002, que dispõe sobre a Lingua Brasileira de Sinais Libras, e o art. 18 da Lei no 10.098, de 19 de dezembro de 2000. Disponível em: <http//:planalto.gov.br>. Acesso em: 10 fev. 2015.

CANCLINI, N. G. Culturas híbridas. São Paulo: EdUSP, 2006.

CANDIDO, A. O direito à literatura. In: Vários Escritos. Rio de Janeiro: Ouro sobre Azul, 2004.

CHIZZOTTI, A. Pesquisas Qualitativas em Ciências Humanas e Sociais.

Petrópolis: Vozes, 2008.

CHKLOVSKI, V. A arte como procedimento. In: TOLEDO, D. de (org.). Teoria da literatura: formalistas russos. Porto Alegre: Globo, 1973.

CULLER, J. Teoria Literária: uma introdução. São Paulo: Becca, 1997.

DAMULAKIS, G. Cooficialização de linguas no Brasil: características, desdobramentos e desafios.

<https://lefufri.files.wordpress.com/2017/12/cooficializac3a7c3a3o-deIc3adnguas-no-brasil-versc3a3o-ii.pdf $>$

EAGLETON, T. Teoria da Literatura: uma introdução. São Paulo: Martins Fontes, 2001.

ESDRAS, D.; GALASSO, B. (Org.). Panorama da Educação de Surdos no Brasil Ensino Superior. Rio de Janeiro: INES, 2017.

GARRAMUÑO, F. Frutos Estranhos: sobre a inespecificidade na estética contemporânea. Rio de Janeiro: Rocco, 2014.

GESSER, A. Libras? Que língua é essa? São Paulo: Parábola, 2009.

HALL, S. A identidade cultural na pós-modernidade. Rio de Janeiro: DP\&A, 2005

JEWITT, C. "Multimodality and literacy in school classrooms". In: Review of Research in Education. Volume 32, 2008. Disponível em: <http://rre.sagepub.com/content/32/1/241.full.pdf>. Acesso em 20 abr. 2018.

KRESS, G. Literacy in the new media age. London: Routledge, la ed., 2003.

PEREIRA, D. C. M.; ABRAHÃO, B. F. O direito do surdo à literatura: por uma educação literária multimodal. Linguagem em (Re)vista, vol. 10, n. 20. Niterói, jul./dez. 2015. 
PESSOA, F. Obra completa. Rio de Janeiro: Nova Aguilar, 1997.

RAMOS, D. C. M. P.; ABRAHÃO, B. F. Literatura surda e contemporaneidade: contribuições para o estudo da Visual Vernacular. Pensares em revista, v. 12, p. 56-72, 2018.

SACKS, O. Vendo Vozes - uma viagem ao mundo dos surdos. São Paulo: Companhia das Letras, 2013.

STAKE, R. E. The art of case study research. Thousand Oaks: SAGE Publications, 1995.

STREET, B. Letramentos Sociais: abordagens críticas do letramento no desenvolvimento, na etnografia e na educação. São Paulo: Parábola Editorial, 2014.

SUTTON-SPENCE, R.; KANEKO, M. Introducing Sign Language Literature: Folklore and Creativity. Palgrave Macmillan, 2016 - versão Kindle.

TODOROV, T. Os Géneros do Discurso. Lisboa: Edições 70, 1978.

Recebido em: 01 de julho de 2019

Aprovado em: 26 de novembro de 2019 